\title{
Correction to: Formative Research on Knowledge and Preferences for Stool-based Tests compared to Colonoscopy: What Patients and Providers Think
}

\author{
John S. Luque ${ }^{1}$ Kristin Wallace ${ }^{2,3} \cdot$ Bridgette F. Blankenship $^{2} \cdot$ Lydia G. Roos $^{4}$ - Franklin G. Berger ${ }^{5}$.
} Nancy R. LaPelle ${ }^{6}$. Cathy L. Melvin ${ }^{2,3}$

Published online: 7 June 2018

(c) Springer Science+Business Media, LLC, part of Springer Nature 2018

\section{Correction to: Journal of Community Health https://doi.org/10.1007/s10900-018-0525-x}

The original version of this article unfortunately contained a mistake. There is a typo in the coauthor name, it should be Franklin G. Berger. The original article has been corrected.

The original article can be found online at https://doi.org/10.1007/ s10900-018-0525-x.

John S. Luque

john.luque@famu.edu

1 Institute of Public Health, College of Pharmacy and Pharmaceutical Sciences, Florida A\&M University, Science Research Center, 1515 South MLK Boulevard, Tallahassee, FL 32307, USA

2 Department of Public Health Sciences, College of Medicine, Medical University of South Carolina, 68 President Street, Charleston, SC 29425, USA

3 Hollings Cancer Center, Medical University of South Carolina, 86 Jonathan Lucas Street, Charleston, SC 29425, USA

4 Health Psychology Ph.D. Program, The University of North Carolina at Charlotte, 9201 University City Boulevard, Charlotte, NC 28223, USA

5 Center for Colon Cancer Research, University of South Carolina, Columbia, SC 29208, USA

6 Division of Preventive and Behavioral Medicine, University of Massachusetts, Worcester, MA 01655, USA 